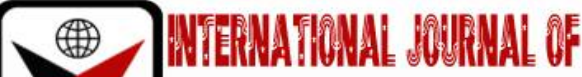

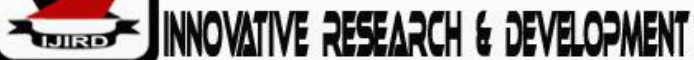

ISSN 2278 - 0211 (Online)

\section{Landslide Disaster in Malaysia: An Overview}

Ayesha Akter
Assistant Professor, Department of Emergency Management,
Patuakhali Science and Technology University, Bangladesh
Megat Johari Megat Mohd Noor
Mrofessor, Department of Environmental Engineering and Green Technology,
University Technology Malaysia, Malaysia
Masa Goto
Professor, Department of Environmental Engineering and Green Technology,
University Technology Malaysia, Malaysia
Shamsunnahar Khanam
Associate Professor, Department of Environmental Science,
Bangladesh University of Professionals, Bangladesh
Ahmed Parvez
Associate Professor, Department of Environmental Science,
Patuakhali Science and Technology University, Bangladesh
Md. Rasheduzzaman
Lecturer, Department of Emergency Management,
Patuakhali Science and Technology University, Bangladesh

\section{Abstract:}

In recent times growing population and accelerative economic condition have led to the construction of high-rise condominiums and expansion of settlements and lifelines over the hilly areas in Malaysia. Due to these development activities risk of landslide disaster events with potential of causalities and economic damage greater than before is increasing. Under such circumstances, number of research efforts conducted in Malaysia has been quickly increasing in recent year, which indicates that landslide is now being considered not only as natural events or a result of design fault, but as a greater risk for the society that needs to be managed in a scientific and systematic way rather than in a haphazard way. The focus of this review is to define knowledge gaps between the current research outcomes and the future research necessities, which are highly recommended to be focused on in order to establish a sustainable society with rapid development and urbanization in Malaysia. From the review it can be concluded that a lot of works have been done so far on model development, mapping and risk zonation but a limited number of researches has been carried out on the causal factor's analysis, sensitivity analysis and socioeconomic characterization. Even few studies have been conceded on response and behavioral aspects of the societies and the crisis management in the events of landslide. It should also be pointed out that, most of the research has been focusing on the, peninsular Malaysia, but not on Sabah and Sarawak in Borneo Malaysia. The reviewers propose to establish an integrated data base on landslides occurred in both Peninsular and Borneo Malaysia. A sound collaborative linkage-based research guideline among the researchers' the policy makers and the residents must be established for better understanding of the facts and figures of Malaysian landslide disaster and its risk.

Keywords: Landslide, classifications, factors, disaster phases, knowledge gaps

\section{Introduction}

Nowadays, a disaster is a common phenomenon and a great concern all over the world. Large numbers of causalities, property damages, livelihood deterioration, destructions of habitat and many other destructive events take place when different kinds of natural and manmade disasters occur. In Malaysia various types of disaster are frequently striking every year. According to the report (Prevention Web 2014) Malaysia had faced flood (62.5\%), storm (12.5\%), wild fire $(8.5 \%)$, landslides $(8.3 \%)$, drought $(4.2 \%)$, earthquake $(2.1 \%)$ and mass movement $(2.1 \%)$ during 15 -years period (1990-2014). The report shows that not only flood and storm, but also landslide has great devastating effects on advanced contemporary societies around the world. This natural disaster causes huge casualties and massive financial losses, especially, in hilly areas. The United States annually faces economic losses of more than USD 2 billion and about 25 to 50 deaths (Li \& Wang 1992) due to landslide. The economic loss in China caused by landslides is estimated to be more than USD 500 million. Landslides are common in hilly and mountainous areas in Malaysia too. During the period between 1963 and 2014, Malaysia had faced many major and medium landslide disasters which caused up to 500 fatalities in total as well 
as substantial loss of properties, collapsed of multistoried buildings, damage on roads and high-ways, and loss of environmental resources. The statistics show that 2.8 landslides per year occur on the average, and of which 1.7 cases result in fatalities and property losses. More than $13.9 \%$ of mortalities were caused by landslides during the years of 19902014 (Prevention Web 2014).

The damages and losses by landslide in Malaysia are partially due to the rapid urbanization and economic development of the country. People have been expanding their economic activities in to the highlands and hilly terrain areas due to the scarcity of suitable low-lying areas available. Cutting of mountain sides and hilly areas for construction of high-rise buildings increases the risk of landslide (Jamaludin \& Ahmad 2006). In addition, hill slope areas are under the pressure of human activities such as deforestation and excavation of slopes for road construction, and land-clearing for agriculture and building construction which are key factors for landslides (Dai et al. 2002). Furthermore, prolonged and intense rainfall, slope instability, topography and soil characteristics also have considerable effects on landslide occurrence (Qasim et al. 2013a; Jamaludin 2006). In absence of appropriate data base, lack in appropriate hill slope technology, cooperation among the organization for establishment of strategies, planning and awareness to reduce landslide risk, the inhabitants of the terrains are still under a high risk. To understand the landslide trend and associated risk factors, the causal analysis based on the historical data set, in the context of Malaysian conditions, is in urgent need. For this reason, this study aims:

- To identify the knowledge gaps for research that need to be addressed immediately by classifying study topics based on the investigation on landslide disaster analysis.

- To summarize the available secondary data to analyze the frequency, trend and risk factors of landslides in Malaysia for the future research works.

\section{Landslide}

Landslide may be defined as the movement of a mass of rock, debris, or earth down a slope. Cruden (1991) defines that a landslide is a rapid displacement of rock, residual soil or sediments adjoining a slope and the center of gravity of moving mass advances in a downward and out-ward directions. Hutchinson defines landslide as a relatively rapid movement of soil and rock on down slope, which takes place characteristically on, discrete bounding slip of surface that's is the moving mass (Hutchinson 1995). Slope movement can occur in five modes; namely fall, topple, slide, spread and flow. These modes are dependent on the type of geologic materials (bed rock, residual soil, earth and their mixture) (Cruden \& Varnes 1996).

\section{Malaysian Experience of Landslides}

This literature (Table 1) provides several perspective and interpretations that tend to relate physical, ecological, social, infrastructure and economic connection.

\begin{tabular}{|c|c|c|c|c|c|c|}
\hline No. & Location & Date & Toll & Loss of Properties & Cost (M) & Scale \\
\hline 1 & Highland Tower & Dec. 11,1993 & 48 & $\begin{array}{l}\text { Collapsed of one block of } \\
\text { 12-story high apartment }\end{array}$ & RM184 & Major \\
\hline 2 & Keramat Permai & May 3, 1995 & - & - & RM 1.3 & Medium \\
\hline 3 & Keramat Permai & Aug. 20, 1995 & & & $<\mathrm{RM} 1$ & Medium \\
\hline 4 & Ampang Jaya & Aug. 20,1995 & & & RM 1.3 & Medium \\
\hline 5 & Ampang Jaya & June 10,1996 & - & - & RM 1.3 & Medium \\
\hline 6 & Bukit Antarabangsa & May 14,1999 & - & - & - & - \\
\hline 7 & Bukit Antarabangsa & May 15,1999 & - & $\begin{array}{l}\text { Access road to the } \\
\text { residential area }\end{array}$ & RM 5.4 & Major \\
\hline 8 & Jln Bukit Antarabangsa & Oct. 5, 2000 & - & Damage of road & - & Medium \\
\hline 9 & Taman Zooview & Oct. 29, 2001 & - & - & - & - \\
\hline 10 & Taman Zooview & Nov. 8,2001 & - & - & RM 1.3 & Major \\
\hline 11 & Taman Hillview & Nov. 20, 2002 & 8 & $\begin{array}{c}\text { Damage of } 1 \text { unit of } \\
\text { bungalow }\end{array}$ & RM17.4 & Major \\
\hline 12 & $\begin{array}{l}\text { Oakleaf Park Condo, } \\
\text { BukitAntarabangsa }\end{array}$ & Nov. 2, 2003 & - & - & - & Medium \\
\hline 13 & $\begin{array}{c}\text { Jalan Bukit Mulia Bukit } \\
\text { Antarabangsa }\end{array}$ & Nov. 7, 2003 & - & - & - & Medium \\
\hline 14 & Jln Tebrau, Dataran Ukay & Feb. 1,2005 & - & - & - & Medium \\
\hline 15 & Kampung Pasir & May 31, 2006 & 4 & $\begin{array}{c}\text { Damage of } 3 \text { blocks of } \\
\text { longhouses }\end{array}$ & RM 21 & Major \\
\hline 16 & $\begin{array}{l}\text { Condo Wangsa Height, } \\
\text { Bukit Antarabangsa }\end{array}$ & April 24, 2008 & - & Damage of 4 vehicles & - & Medium \\
\hline 17 & $\begin{array}{c}\text { Tmn Bukit Mewah, Bukit } \\
\text { Antarabangsa }\end{array}$ & Dec. 6, 2008 & 5 & $\begin{array}{c}\text { Damage of } 14 \text { units of } \\
\text { bungalows }\end{array}$ & RM 7.6 & Major \\
\hline 18 & $\begin{array}{c}\text { Wangsa Height, Bukit } \\
\text { Antarabangsa }\end{array}$ & Sep. 19, 2009 & - & - & - & Medium \\
\hline 19 & Ukay Club Villa & April 2010 & - & - & RM 1.3 & Medium \\
\hline
\end{tabular}




\begin{tabular}{|c|c|c|c|c|c|c|}
\hline No. & Location & Date & Toll & Loss of Properties & Cost (M) & Scale \\
\hline 20 & Bukit Antarabangsa & Aug. 2010 & - & - & RM 1.3 & Medium \\
\hline 21 & Ukay Perdana & Feb. 2011 & - & - & RM 1.3 & Medium \\
\hline 22 & Selangor & 21 May 2011 & 15 & - & - & Medium \\
\hline 23 & The Puncak Setiawangsa & 29 Dec 2012 & - & $\begin{array}{c}\text { Shop houses and double- } \\
\text { story terrace houses were } \\
\text { ordered to move }\end{array}$ & - & Medium \\
\hline 24 & Putra Heights & 04 Jan 2013 & - & $\begin{array}{c}\text { Several vehicles to be } \\
\text { submerged }\end{array}$ & - & $\begin{array}{c}\text { No } \\
\text { update }\end{array}$ \\
\hline 25 & Camerun high land & 2013 & 7 & Damage of infrastructure & RM 3.5 & Major \\
\hline 26 & Bukit lajan kualampur & 9 May 2014 & - & Blocked the road & - & - \\
\hline
\end{tabular}

Table 1: Recent (From 1993 To 2014) Scenarios of Landslide in Malaysia

The trend of landslide disaster occurrence is gradually increasing (figure 1). The reason of raising number of landslides is now a matter of research but commonly they are due to slope failure. These seem that mostly slope failure are triggered by a localized rainfall. But associated inherent weaknesses of the rock or soil combined with human activity like heavy condominium construction and poor drainage system may have the contributing role. Because hilly and terrain region are highly vulnerable and sensitive to human alterations (water streams diversions, cut off vegetative coverage) compare to the plain land. Mostly collapsing condominiums which responsible for both life loss and economic damages.

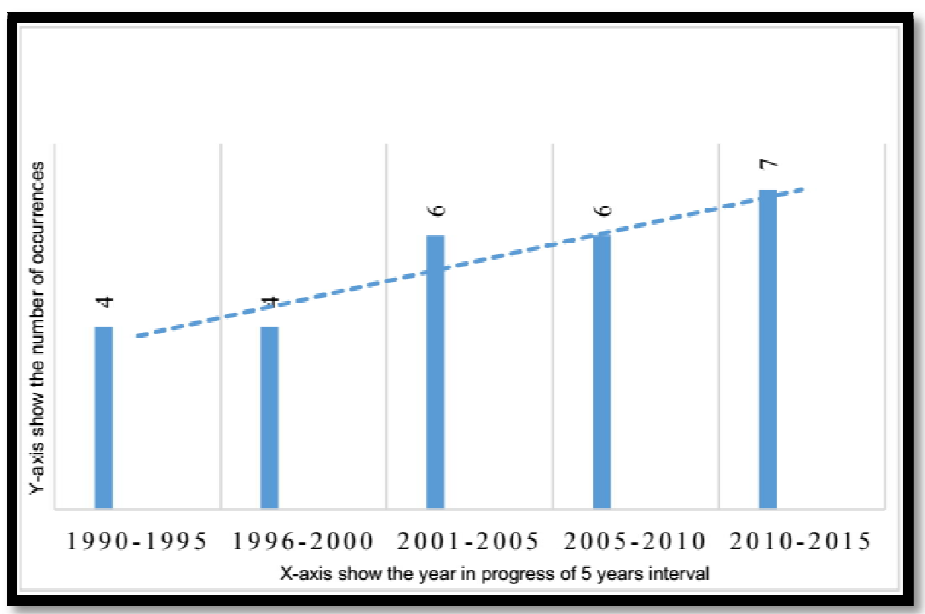

Figure 1: Trend of Landslide Disaster in Malaysia Showing an Upward Movement

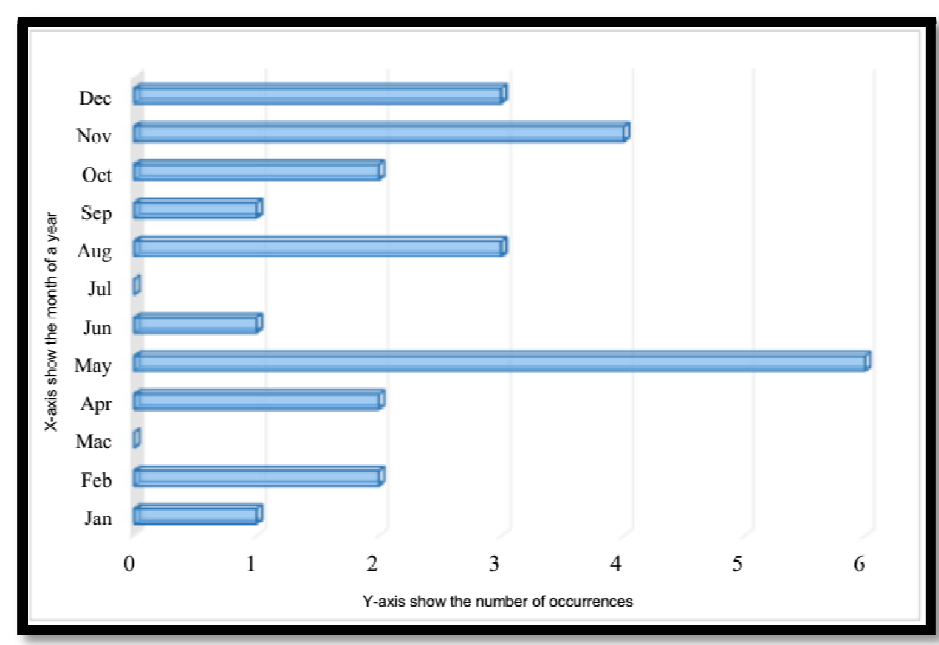

Figure 2: Month Wise Landslide Occurrence in Malaysia 


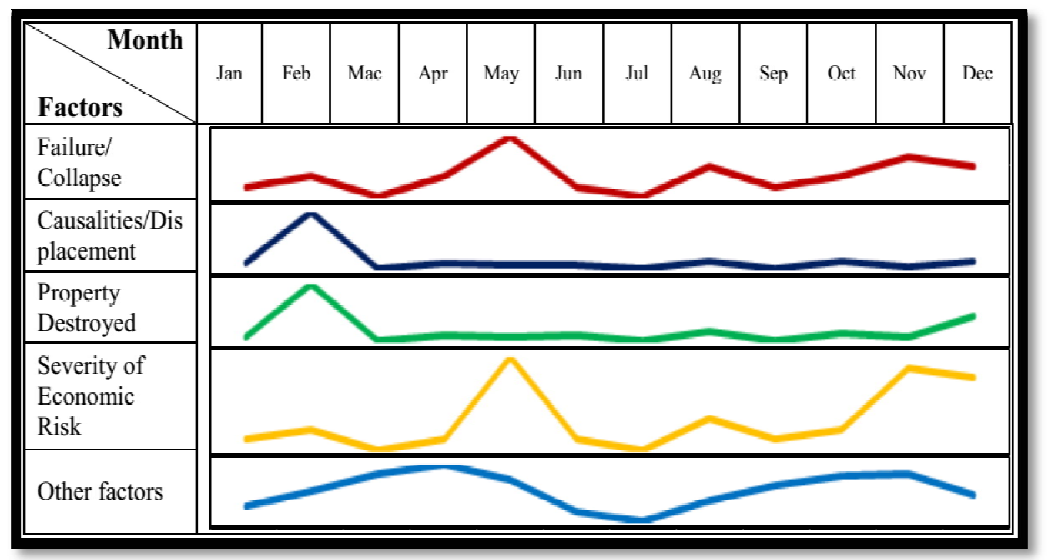

Figure 3: Month Wise Landslides Hazard Calendar in Malaysia

A multi-criteria analysis (Figure 3) shows that in the month of February and August all the factors are positively correlates each other's. And the month of May and November (Figure 2) have the higher number of landslide experience. Considering the climatic parameters (Rain fall and temperature) November is the rainy season in Malaysia that may be the reason of slope failure whereas moth of May are under the dry spell but the highest number of landslide occurred in May, which indicates presence of other factors that may be a new research scope for landslide disaster impact reduction.

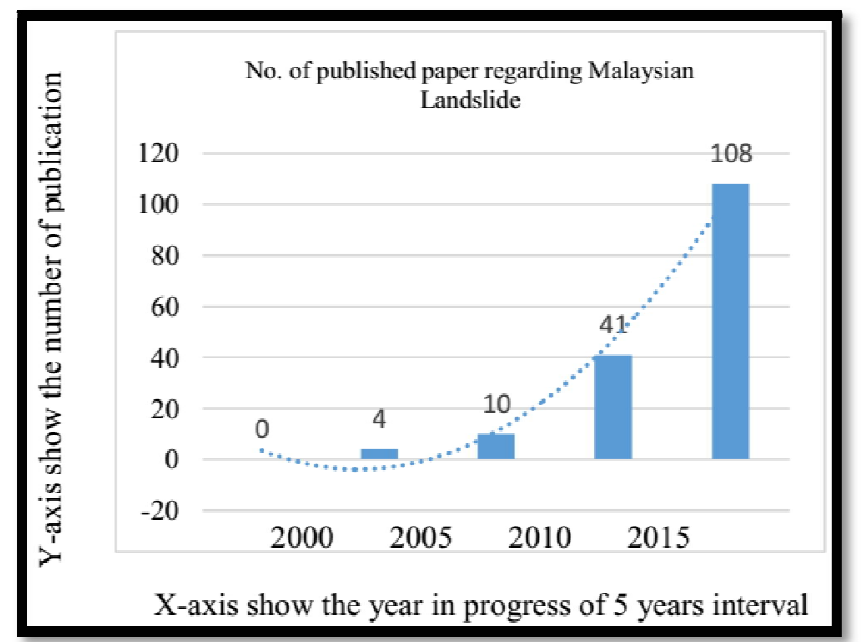

Figure 4: Increasing Trend of Articles Published in the Different Journal Regarding Malaysian Landslides

Due to massive destruction history of landslides in Malaysian society the university scholars and technical professionals has already take it in their account to do more research in advanced management aspects. That is why last few years the scientific articles are assimilation to the web of knowledge base. It is found that (Figure. 4) the rate of increasing number of published articles is gradually upward. Besides the increasing number of articles on landslide disaster in Malaysia, the number of diversified journals also increased because of its dynamic scoping characters. Some geoscience-based journals are mostly covering the research focusing their different angle of scopes.

\begin{tabular}{|c|c|c|}
\hline Sl. & Name of the Journal & No. Pub. \\
\hline 1 & Arabian journal of geosciences & 6 \\
\hline 2 & Environmental earth sciences & 4 \\
\hline 3 & Landslides and engineered slopes: from the past to the future, vols 1 and 2 & 4 \\
\hline 4 & Natural hazards & 3 \\
\hline 5 & Sains Malaysiana & 3 \\
\hline 6 & Landslides & 3 \\
\hline 7 & Geomatics natural hazards \& risk & 2 \\
\hline 8 & IEEE transactions on geoscience and remote sensing & 2 \\
\hline 9 & International journal of remote sensing & 2 \\
\hline 10 & Expert systems with applications & 2 \\
\hline 11 & Remote sensing for environmental monitoring, gis applications, and geology ix & 2 \\
\hline 12 & Geomorphology & 2 \\
\hline 13 & Landslides and climate change: challenges and solutions & 2 \\
\hline
\end{tabular}

Table 2: Articles Collected from the Journals Used in the Study 
According to the (Sassa et al. 2009) stated in the appropriate topics of landslide about 21 as he proposed in his articles. Combining this topic in light with phases of disaster management (Salem et al. 2011) this study proposed a classification of published paper into eight following categories.

Classification of papers on landslides disaster

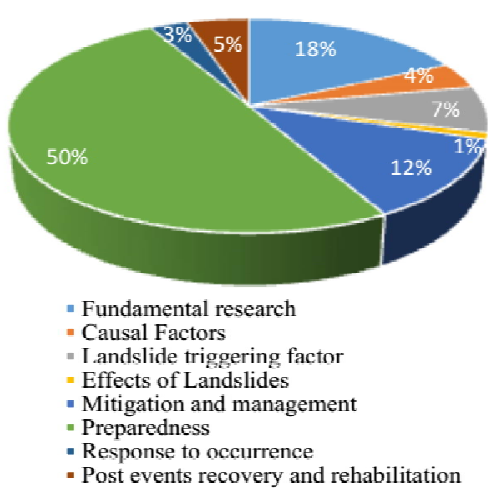

Figure 5: Classification of Papers on Landslides Disaster in Malaysia from Web of Science Records

- Fundamental research

- Research on Causal factors identification

- Landslide triggering factors investigation

- Effects of landslide disaster analysis

- Landslide mitigation, management and resilient development research

- Landslide disaster preparedness research

- Response to occurrence of landslide

- Post landslide recovery and rehabilitation study

\section{1. Class 1 (Fundamental Research)}

This category of research includes landslide dynamics, mechanism and process. Geology, geomorphology, geotechnical geo physics of landslide also included under this segment. There are 18\% papers have been matched with this category so far information found from the data base. (Jebur et al. 2015) proposed a user-friendly BSM (Bivariate Statistical Modeler) for numerous applications, such as, natural hazard, mineral, hydrological and other engineering and environmental applications. From (Manap et al. 2014) investigated the application of the probabilistic based frequency ratio (FR) model for mapping ground water potential at Langat basin, Malaysia. He used the frequency ratio coefficients of the hydrological factor to produce map. On the other hand (Simon et al. 2015) assessed the influence of development on land slide occurrence using 3 years' time series, based on two indicators; land use and road density and showed a positive relationship with each of the factors. (Jebur et al. 2015) who conducted research at Gunung pass, detected a vertical slope movement, which was highly vegetated tropical area. He used L-band InSAR techniques for detecting vertical displacement.

Some of the extensive soil-based research also conducted to describe the Malaysian landslides. (Pradhan et al. 2012) who is one of the pioneer researchers observed soil erosion by universal soil loss equation (USLE) method at Penang Island. He found a correlation between soil erosion and landslide events, which are directly proportional to each other. The similar kind of study was also done by (Khosrokhani \& Pradhan 2013). She observed and assessed soil erosion with its dynamic characteristics at Kuala Lumpur metropolitan city using universal soil loss equation.

\subsubsection{Knowledge Gaps}

A lot of work is still need to done for the understanding of Malaysian landslides mechanism. There is some lack of knowledge in the area of fundamental research regarding debris transportation process; the mechanism of mass change is an important topic in the study of debris flow, avalanches and sliding of land. Basal erosion is considered as a dynamic interaction among the moving material and the entrained basal top-soil shearing along with non-slip contact surface can be an area for new observation. On the other hand, peninsular Malaysia is full of mountainous ridges, how erosion occurred in that area can be described significantly by emergence of fractal structures in geomorphological phenomena (Czirók et al. 1997). Besides this thermo-mechanical model can be applied to understand large scale, deep seated landslides consisting of a coherent mass sliding. In this model the considerable parameter is temperature rising in the slip zone due to heat produce by the friction. Furthermore, a sliding block model is very much fit in to describe the mountainous high-speed landslides. It can predict by simulating the soil mass from the onset of the event including travel speed of mass material and hazard areas. This technique will be more useful for the prediction of landslide events in Sabah and Sarawak. Finally, more research is necessary to determine sensitivity factors other than both temperature and precipitation, magnitude, frequency of landslide changes in relation to recent climate and future climate change situations particularly in tropical forest areas in Malaysia. 


\subsection{Class 2 (Causal Factors Identification)}

Under this category of research landslide occurring factors, which have at least potentiality to contribute such happening. There are $4 \%$ articles have been related with this category. We can subdivide these causal factors into two: natural and manmade factors. On the other hand we can divided it in to three sub-categories: Intrinsic factors (which allow other factors to act more efficiently) includes steep slope, deep weather soil, high clay content and high annual rainfall, introductory factors (which make the slope vulnerable to slide) includes human activities, deforestation, land use change, construction of high raise building, high way, poor drainage system, excavations etc., Initiating factors (which finally initiate the movement) includes earth quake and heavy rainfall.

(Alkhasawneh et al. 2014) specified the importance of 21 factors causing the landslides in his study carried out a wide area of Penang Island which may represents the peninsular Malaysia. Among all the factors he showed slope angle, distance from drainage, surface area, slope aspects and cross curvature is the most important factors. (Parasad et al. 2012) used woody vegetation to observed the growth for providing low cost and environmentally suitable alternative to the conventional methods of slope stabilization using the finite element software PLAXIS. The result showed that the factors of safety of the slopes increased significantly by the reinforcement effects of woody vegetation. (Douglas et al 1999) investigated 10 years at Danum Vally, Sabah and provided a strong evidence of the role of extreme events on the erosion process in tropical forest areas.

\subsubsection{Knowledge Gaps}

Regardless of these causal factors some other factors may include sliding belt, disturbed rocks, ancient colluvium, slope wash, topographic scarp, and elevated ground water table and drainage network for example, dendritic etc. Moreover, a landslide data base or digital landslide inventories is highly demanded for the better assessment of landslide and future master plan to reduce the potential risk, in Malaysia. It will be more useful if geo-environmental factors, triggering factors and elements at risk are added to the information data base. A complete data base gives insights into landslide location, types, dates, frequency of occurrence, and state of activity, severity, size, failure mechanism, and causal factors. In line with additional information and complementary data of core attributes like geographical coordinates, landslide site name along with region and country, last reactivation, state of activity, volume of surface extent may be included with data base. To make the inventory a creative, information of landslide geometry (surface dimension and depth of failure surface), geology (structure and material properties), hydrogeology, land coverage, triggering factors, impact, causalities and damages, remedial measures, surveying methods, surveyor's name and bibliographical references will be more appropriate.

From the figure 6 it is clear that contributing factors of world landslides geological and ground conditions are covering the $43 \%$ which indicates the natural control. But for Malaysian cases (figure 7) we found that about $58 \%$ are design errors. The results are also similar with (Gue \& Tan 2006); he found that $60 \%$ are inadequacy in design. This is results of lack of understanding and appreciation of the subsoil conditions and geotechnical issues. It also includes the decision errors comprising with misinterpretation and miscalculation. It indicates that if we minimize these design errors, we can reduce the risk so a new research may be conducted here to resolve this matter.

\subsection{Class 3 (Landslide Triggering Factors Investigation)}

According to (Griffiths 1999) Causes of landslides are two groups:

- Preparatory factors

- Triggering factors

Heavy rainfall or snow melt, earthquake shaking, volcanic eruption and erosion are the triggering factors that created an instantaneous change in the stress-strain associations in the slope resulting in movement. Geological conditions, groundwater conditions, geo-morphological conditions, climatic factors, seismic activity, weathering, and manmade factors are the main factors which are called preparatory factor. This category of research includes direct contributing factors which can cause the disaster. There are 7\% papers have been complemented with this category.

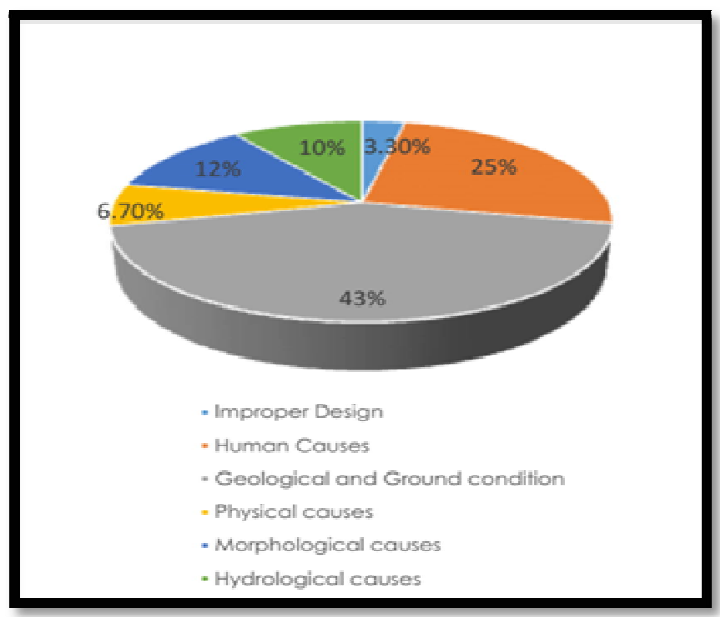

Figure 6: Contributing Factors of Landslides 


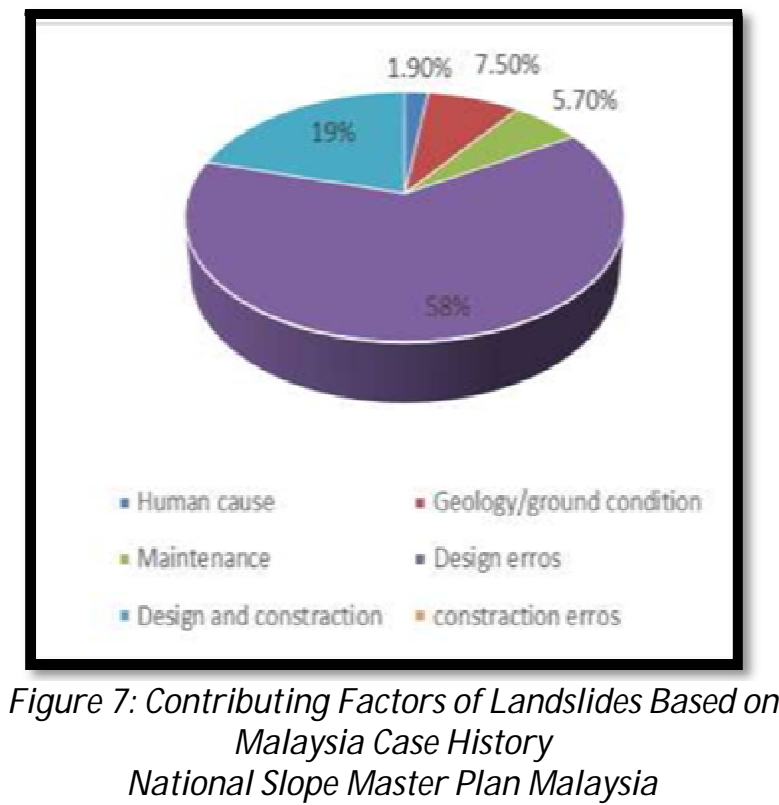

Most of the landslides that caused most damaged in Malaysia occurred in man-made slopes. Examples of such landslides include the Highland Towers in 1993, Bukit Lanjan rockslide in 2003, Taman Zooview in 2006, Bukit Antarbangsa in 2008. (Komoo et al 2011) interpreted that in Malaysia most of the landslides occur because of slope failure that is manmade slope of highway and resident. (Qasim et al. 2013b) mention that condition of sub soil, geology, ground water and underground piping should be considered for investigation the causal factor. (Saadatkhah 2014) demonstrated that prolonged rainfall has played a vital role for slope failure using spatiotemporal regional modeling coupled with rainfall induced slope failure. (Matori et al. 2012) reported the effect of monsoonal selected geospatial data in landslide modeling in Cameron Highlands. They used geographical information system coupled with land surface temperature LST by developing a model Based map of landslide. (Hassaballa et al. 2014) extract the soil moisture over the areas of Bukit Antarabangsa using microwave remote sensing to examine the impact of soil moisture content on landslide occurrence. They stated that 6th December 2008 recorded heavy rain fall resulted in a raise of ground water table causing the landslide. Frequent and prolong rainfall is a triggering factor of landslide in Malaysia. As a tropical country, Malaysia enjoys $2400 \mathrm{~mm}$ rainfall annually (Li \& Wang1992) added that rainfall intensity and slope failure have a good co-relation. He also mentions that the ground water level also playing important role in triggering the landslide, which is always overlooks as one of the initial factors of landslide.

\begin{tabular}{|c|c|}
\hline Rainfall Intensity & Slope Condition \\
\hline $25 \mathrm{~mm} /$ day & Show signs of surface erosion \\
\hline $50 \mathrm{~mm} /$ day & Surface erosion intensify \\
\hline $100 \mathrm{~mm} /$ day & Stability deteriorate, marginally, stable slope may deform and move \\
\hline $150 \mathrm{~mm} /$ day & Marginally stable slope may deform or collapse \\
\hline $200 \mathrm{~mm} /$ day & Marginally stable slope may deform or collapse. Stable slope may also show signs of instability \\
\hline $250 \mathrm{~mm} /$ day & Stable and vegetated slope may also deform or collapse. \\
\hline
\end{tabular}

Table 3: Rainfall Intensity and Slope Failure Correlation (Li \& Wang1992)

(Mukhlisin et al. 2015) analyzed 15 event of rainfall prompted landslides in Ulu Klang, and found that all of the event were triggered by landslide but some events casual factors were different that was inadequate slope design, improper design, construction method, poor maintenance of the internal drainage system, off slope and retaining structural soil type and slope gradient. In Malaysia most slope failure occurred by manmade slope development in hilly terrain areas, such as highland tower at kualampur in 1993, bukit lanjan rockside in 2003, taman zooview in 2006, and again bukit lanjan at 2014. In 1993 the landslide event of Ulu Klang reported by (MPJA 1994) mentioned some of the reasons such as soil movement, surface runoff due to improper drainage facility cut of hill slope. Not only the human factor but also some natural factor associated with landslide such granite terrain which weathered deeply in geological timescale that's why tropical Malaysia experience many landslides. (Chigira et al. 2011) isolated some region of peninsula Malaysia. Earthquake is the major triggering factor next to the intensive rainfall. The shaking produced by earthquake cause an increase in the load down the slope and can also decreases the shear strength and both effects can cause the release of debris flow. One of the landslides evented in Sabah is reported earthquake as the triggering factors. Weathering and surface fracturing also considered as a vital triggering factors for sliding in some parts of the world (Dragićević 2010).

\subsubsection{Knowledge Gaps}

A regional basis investigation for understanding the above triggering potentialities and mapping of vulnerable zone can be a new research arena. In addition to this, application of digital tools, geographical information system, digital 
image processing, digital photogrammetry, global positioning through using various models for analyzing the contribution of triggering factors on landslide occurrence can enhance the better research outcomes in Malaysia.

\subsection{Class 4 (Impacts Of Landslide Disaster Analysis)}

\begin{tabular}{|c|c|c|c|}
\hline Date & Location & Death & Cost MRM \\
\hline May 61 & Ringlet Cameron highland, Pahang & 16 & 3.48 \\
\hline Oct 73 & KAMPUNG kacag puith ipoh & 42 & 64.78 \\
\hline Dec 95 & Highland ampang selangr, tower, & 48 & 184.9 \\
\hline Jun 95 & Km 39 lebuhraya kl karak & 20 & 48.3 \\
\hline Dec 96 & Keningau, Sabah 302 & 45 & 8.9 \\
\hline Jan 96 & Km 303 North-South Expressway Gunung & 11 & 6.7 \\
\hline Tug 96 & Pempurung, Perak & & 69 \\
\hline Feb 99 & Gelam Sandakan, Saba & 44 & 458.9 \\
\hline Jan2 & Simunjan, Sarawak & 302 & 28 \\
\hline Nov 3 & KM 21.8 NKVE Bukit Lanjan, Selangor & 8 & 36 \\
\hline Apr 05 & Kpg Melayu Bt 11, punching, Selangor & & 47 \\
\hline May 06 & Taman bukit zooview, hulu klang, Selangor & 4 & 20.7 \\
\hline Apr 06 & KM 33 Jln Simpang pulai Cameron highland & 35 & 4.6 \\
\hline
\end{tabular}

Table 4: Major Land Slide in Malaysia and Estimated Loss of Cost

This category of research includes the impacts of landslide on socioeconomic system, ecosystems management and short term or long-term urbanization process. There are 1\% papers have been matched with this category so far information found from the data base. Malaysia has a high concentration of development of express ways, high ways, high raises condominium, tunnels, and monorail etc. in hilly terrain and peninsular region close proximity to build-environment and natural environment. Because of the high annual rainfall along with some others induced factors these man-made environment and natural hillside would pose a risk to public as reported by death tool of 600 and adequate property damages (Table 4) since 1960 to till date (Azmi et al. 2013).

\subsubsection{Knowledge Gaps}

The following area of research is proposing by the present study cost-benefit analysis and livelihood analysis. Under the classification of effects of landslide disaster economic analysis, damage, loss and need assessment, effects on human society, environmental impact assessment and social impact assessment, risk analysis of building damages induced by landslide disaster impacts may be the major focusing areas. In spite of frequent deadly landslide in Malaysia, literature is not available on socio-economic and environmental effects. Very few works have been published in this area except some of the technical report commissioned by government.

\subsection{Class 5 (Landslide Mitigation, Management and Resilient Development Research)}

This category of research includes landslide study, which includes the physical, social and institutional vulnerability of the people as well as scientific clarification and indigenous solution of mitigation measures. There are $12 \%$ papers have been matched with this category so far information found from the data base. (Halim \& Normaniza 2015) showed that plant density was inversely related to the soil saturation level (STL) and erosion rate on the slope. The redistribution of infiltrated rainwater in the soil mass could be the reason for the slow response of failure mechanism to rain fall. (Mariappan et al. 2010) has proposed some comprehensive program to reduce the loss of landslide through creation of early warning and monitoring system better policy and effective implementation, outlining design procedure, creation of local hazard mapping, land use management, building, grading control etc.

\subsubsection{Knowledge Gaps}

Social vulnerability index may apply to the landslide hazard prone areas. Variables representing the social vulnerability of the different states of Malaysia are needed to be selected after application of correlation tests. Furthermore, a novel risk assessment method measuring the resiliency of landslide disaster of hill slope community need to be structured for implementation of risk vulnerability analysis, performance of disaster mitigation approaches and reduction of future life loss and property damages.

\subsection{Class 6 (Landslide Disaster Preparedness Research)}

This category of research includes all sorts of consideration prior to the landslide need for predicting, forecasting, hazard mapping, Risk assessment, Emergency preparedness, Real time monitoring, research development and training etc. There are $50 \%$ papers have been matched with this category so far information found from the data base. (Saadatkhan et al. 2014b) applied transient rainfall infiltration and grid-based regional slope stability analysis method (TRIGRS) for unsaturated initial conditions is used to complete transient response of pore pressure during rainfall periods and consequent changes in the safety factors. (Pradhan \& Youssef 2010) presented landslide hazard analysis at Cameron area using geographic information system and remote sensing data and found that frequency ratio model is better in prediction of landslide than bivariate logistic regression model. (Razak et al. 2013) evaluates the suitability of ALS (Airborne Laser 
Scanning) for generating an optimal DTM (Digital Terrain Model) for mapping land use in the Cameron High land, Malaysia's and found that ALS derived DTMs allowed mapping and classifying landslide beneath equatorial mountainous forests leading to a better understanding of hazardous geomorphological problem in Malaysia as well as tropical region. (Pradhan et al. 2014) estimate the land subsidence (sinkhole) hazard at the Kinta Valley of Perak, using GIS and RS techniques and finally prepared probability map. From the above literature it is clear that mapping-based susceptibility and model analysis has been covered most of the hot spot of landslide occurred areas.

\subsubsection{Knowledge Gaps}

But a lot of information gaps are still need to be under research. Most of the developed countries use satellite remote sensing as a tool in disaster management and sustainable development research. Prediction of the spatiotemporal distribution of landslides using real time satellite rainfall system may be a new scope of research. In relation to this "2006 Tokyo Action Plan" which enhances the risk conscious reconstructions can be the applicable research in city Centre. OR models applicable for integrated community-based program, Humanitarian logistics in Malaysia, Emergency Medical Rescue team etc. Considering the disaster readiness aspects this research may extend up to natural hazard and risk communication strategy among the multi ethnic community and community trauma recovery program after the landslide occurrence can give a whole shape.

\subsection{Class 7 (Response to occurrence of landslide)}

This category of research includes warning, evacuation, search and rescue, trauma management, volunteerism dynamic modification of technology, amendment on the current rules and regulations by the previous landslide experience, reverse changes in moving to risk prone areas, multistory to single story etc. There are $3 \%$ papers have been harmonized with this category. (Abedin et al. 2005) initiated a study to classify and predict potential erosion induced landslide locations of occurrence used ROM scale to determine the soil susceptibility for failure in terms of its soil erodibility index value and rain fall data of both Frasher Hill and Genting Highlands. This result showed that rainfall risk frequency is at the highest risk in the month of November and September.

\subsubsection{Knowledge Gaps}

That is why, geo-hydrological risk management and preparedness of Malaysian Civil Protection Authority for warning and evacuation in response to landslide may be an effective research program. Furthermore, post occurrence of landslide, reconstruction management using public perception and lesson learned can be added with the research portfolio.

\subsection{Class 8 (Post Landslide Recovery and Rehabilitation Study)}

This category of research includes slope management, slope stabilization, Life pole stabilization, debris management, traffic management, temporary shelter management, insurance management and relief management etc. There are 5\% papers have been accorded with this category. (Ali et al. 2010) studied on the use of vegetation for slope protection. This was a bioengineering approach to documented root mechanical properties. He studied two para meter pull-out and tensile strength to select the best root performance of the trees. Finally, he suggested plant using for slope stabilization work. (Gui et al. 2008) investigated a compilation of site reconnaissance, topography survey, subsurface investigation, laboratory testing and back analysis to examine the relationship between the landslides and the rainfall. He confirmed that landslide was indeed related to the long period rainfall.

\subsubsection{Knowledge Gaps}

Future research under this class like vegetation recovery and landscape change assessment may helpful. Automated system enables emergency planners to estimate the expected displacement of families for optimizing postdisaster temporary housing allocations may value the good research scheme also.

\section{Conclusion}

This study synthesizes the previous landslide history and critically reviews the landslides previous history, causal factors and research domain. Further, a brief summary of landslide disaster management research scope in Malaysia. Moreover, limited causes of landslide have been investigated and reported in developing area that had damaged the property or poses a greater risk to life. Besides this aspect some other issues may appear as a hindrance of the progressive work, need to be addressed. For sustainable solution of the land slide disaster may broadly cover the socioeconomic and Ecology centered key areas which are identified throughout the study in different classes are applicable for future research.

\section{Acknowledgement}

This work is partially supported by FRGS Research Grant, with Vote No. R.K130000.780. 4F655 under Ministry of Higher Education (MoHE) and MJIT Student Incentive Programme. 


\section{References}

i. Abdullahi, S., Pradhan, B., Mansor, S., \& Shariff, A. R. M. 2015. GIS-based modeling for the spatial measurement and evaluation of mixed land use development for a compact city. GIScience \& Remote Sensing, 52(1), 18-39.6

ii. Azmi, A. S. M., Salleh, W. A. R. W. M., \& Nawawi, A. H. 2013. Cognitive Behaviour of Residents Toward Living in Landslide Prone Area: Ulu Klang.Procedia-Social and Behavioral Sciences, 101, 379-393., ISSN 1877-0428, http:// dx.doi.org/ 10.1016/ j.sbspro.2013.07.212.

iii. Ali, F. 2010. Use of vegetation for slope protection: Root mechanical properties of some tropical plants. International Journal of Physical Sciences,5(5), 496-506.

iv. Alkhasawneh, M. S., Ngah, U. K., Tay, L. T., \& Isa, N. A. M. 2014. Determination of importance for comprehensive topographic factors on landslide hazard mapping using artificial neural network. Environmental earth sciences, 72(3), 787-799.

v. Chigira, M. A. S. A. H. I. R. O., Mohamad, Z. A. I. N. A. B., Sian, L. C., \& Komoo, I. 2011. Landslides in weathered granitic rocks in Japan and Malaysia. Bulletin of the Geological Society of Malaysia, 57, 1-6.

vi. Cruden, D. M., and D. Varnes. 1996. Landslide types and processes."Landslides, Investigation and Mitigation, ed. AK Turner and RL Schuster. Transportation Research Board, Special Report 247 (85): 36475.

vii. Cruden, D.M., 1991. A simple definition of a landslide. Bulletin of the International Association of Engineering Geology 43, 27 - 29.

viii. Czirók, A., E. Somfai, and T. Vicsek. "Fractal scaling and power-law landslide distribution in a micromodel of geomorphological evolution." Geologische Rundschau 86, no. 3 1997: 525-530.

ix. Dai, F. C., Lee, C. F., \& Ngai, Y. Y. 2002. Landslide risk assessment and management: an overview. Engineering geology, 64(1), 65-87.

x. Douglas, I., Bidin, K., Balamurugan, G., Chappell, N. A., Walsh, R. P. D., Greer, T., \& Sinun, W. 1999. The role of extreme events in the impacts of selective tropical forestry on erosion during harvesting and recovery phases at Danum Valley, Sabah. Philosophical Transactions of the Royal Society B: Biological Sciences, 354(1391), 1749-1761.

xi. Dragićević, S. 2010. Modeling the dynamics of complex spatial systems using GIS, cellular automata and fuzzy sets applied to invasive plant species propagation. Geography Compass, 4(6), 599-615.

xii. Gonghui Wang, Kyoji Sassa 2009: Seismic loading impacts on excess pore water pressure maintain landslide triggered flowslides. Earth Surface Processes and Landforms 34(2):232-241.

xiii. Griffiths, J. S. "Proving the occurrence and cause of a landslide in a legal context." Bulletin of Engineering Geology and the Environment 58, no. 1 1999: 75-85.

xiv. Gue, S.S. and Y.C. Tan, 2006. Landslides: Cases Histories, Lessen Learned and Mitigation Measures. Paper presented at the Sinkhole, Structure Failure: Myth or Science? IpoH, Malaysia.

xv. Gui, M. W., \& Han, K. K. 2008. A case study on rainfall infiltration effect on the stability of two slopes. Civil Eng. Dept., National Taipei Univ. of Technology, Taipei, China.

xvi. Halim, A., \& Normaniza, O. 2015. The effects of plant density of Melastoma malabathricum on the erosion rate of slope soil at different slope orientations. International Journal of Sediment Research, 30(2), 131-141.

xvii. Hassaballa, A. A., Althuwaynee, O. F., \& Pradhan, B. 2014. Extraction of soil moisture from RADARSAT-1 and its role in the formation of the 6 December 2008 landslide at Bukit Antarabangsa, Kuala Lumpur. Arabian Journal of Geosciences, 7(7), 2831-2840.

xviii. http:// www.preventionweb.net/ files/ 10712_MALAYSIAOfficialStatementFinal.pdf

xix. http:/ / www.starproperty.my/ index.php/articles/ property-news/ predicting-future-landslides-in-malaysia/

xx. Hutchinson, J. N. "Keynote paper: landslide hazard assessment." Landslides. Balkema, Rotterdam 1995: 1805-1841.

xxi. Jamaludin, S., \& Ali, F. 2011. An overview of some empirical correlations between rainfall and shallow landslides and their applications in Malaysia.Electron J Geotech Eng, 16, 1429-1440.

xxii. Jamaludin, Suhaimi, and Ahmad Nadzri Hussein. "Landslide hazard and risk assessment: The Malaysian experience." Notes (1993).

xxiii. Jamaludin, Suhaimi, Bujang BK Huat, and Husaini Omar. "Evaluation and Development of Cut-Slope Assessment Systems For Peninsular Malaysia In Predicting Landslides In Granitic Formation." Jurnal Teknologi 44, no. 1 (2012): 31-46.

xxiv. Jebur, M. N., Pradhan, B., \& Tehrany, M. S. (2015). Manifestation of LiDAR-derived parameters in the spatial prediction of landslides using novel ensemble evidential belief functions and support vector machine models in GIS. Selected Topics in Applied Earth Observations and Remote Sensing, IEEE Journal of,8(2), 674-690.6

xxv. Jebur, M. N., Pradhan, B., Shafri, H. Z. M., Yusoff, Z. M., \& Tehrany, M. S. (2015). An integrated user-friendly ArcMAP tool for bivariate statistical modelling in geoscience pplications. Geoscientific Model Development, 8(3), 881-891.

xxvi. Khosrokhani, M., \& Pradhan, B. (2014). Spatio-temporal assessment of soil erosion at Kuala Lumpur metropolitan city using remote sensing data and GIS.Geomatics, Natural Hazards and Risk, 5(3), 252-270.

xxvii. Komoo, Ibrahim, Sarah Aziz, and Lim Choun Sian. "Incorporating the Hyogo Framework for Action into landslide disaster risk reduction in Malaysia."Bulletin of the Geological Society of Malaysia 57 (2011): 7-11.

xxviii. Li, T., Wang, S., 1992. Landslide Hazards and their Mitigation in China. Science Press, Beijing, 84 pp.

xxix. Manap, M. A., Nampak, H., Pradhan, B., Lee, S., Sulaiman, W. N. A., \& Ramli, M. F. 2014. Application of probabilisticbased frequency ratio model in groundwater potential mapping using remote sensing data and GIS. Arabian Journal of Geosciences, 7(2), 711-724.

xxx. Mariappan, S., Ali, F., bin Mohamad, A., Abdullah, C. H., Hassan, N. R. N., Chong, S., \& Huat, L. T. 2010. Undertaking loss reduction measures to prevent slope failures. Scientific Research and Essays, 5(2), 119-129. 
xxxi. Matori, A. N., Basith, A., \& Harahap, I. S. H. 2012. Study of regional monsoonal effects on landslide hazard zonation in Cameron Highlands, Malaysia. Arabian Journal of Geosciences, 5(5), 1069-1084.

xxxii. MPJA, 1994. Report of the Technical Committee of investigation on the collapse of Block 1 and the Stability of Block 2 and 3 Highland Towers Condominium Hulu Klang Selangor Darul Ehsan.

xxxiii. Mukhlisin, M., Matlan, S. J., Ahlan, M. J., \& Taha, M. R. 2015. Analysis of Rainfall Effect to Slope Stability in Ulu Klang, Malaysia. Jurnal Teknologi,72(3).

xxxiv. Pradhan, B., \& Youssef, A. M. 2010. Manifestation of remote sensing data and GIS on landslide hazard analysis using spatial-based statistical models.Arabian journal of geosciences, 3(3), 319-326.6Pradhan, B., Abokharima, M. H., Jebur, M. N., \& Tehrany, M. S. 2014. Land subsidence susceptibility mapping at Kinta Valley (Malaysia) using the evidential belief function model in GIS. Natural hazards, 73(2), 1019-1042.6

xxxv. Pradhan, B., Chaudhari, A., Adinarayana, J., \& Buchroithner, M. F. 2012. Soil erosion assessment and its correlation with landslide events using remote sensing data and GIS: a case study at Penang Island, Malaysia.Environmental monitoring and assessment, 184(2), 715-727.

xxxvi. Pradhan, B., Latif, Z. A., \& Aman, S. N. A. 2012. Application of airborne LiDAR-derived parameters and probabilisticbased frequency ratio model in landslide susceptibility mapping. In Applied Mechanics and Materials(Vol. 225, pp. 442-447).

xxxvii. Prasad, A., Kazemian, S., Kalantari, B., Huat, B. B., \& Mafian, S. 2012. Stability of tropical residual soil slope reinforced by live pole: experimental and numerical investigations. Arabian Journal for Science and Engineering, 37(3), 601618.

xxxviii. Qasim, Sadaf, I. S. H. Harahap, Syed Osman, and Syed Baharom. "Causal factors of Malaysian landslides: A narrative study." (2013a). Journal of Applied Science , Engineering Technology 5 (7): 2303-2308.

xxxix. Qasim, Sadaf, I. S. H. Harahap, Syed Osman, and Syed Baharom. "Causal factors of Malaysian landslides: A narrative study." (2013b). Journal of Applied Science, Engineering Technology 5 (7): 2303-2308.

xl. Razak, K. A., Santangelo, M., Van Westen, C. J., Straatsma, M. W., \& de Jong, S. M. 2013. Generating an optimal DTM from airborne laser scanning data for landslide mapping in a tropical forest environment. Geomorphology,190, 112125.6

xli. Saadatkhah, N., Kassim, A., \& Lee, L. M. 2014a. Hulu Kelang, Malaysia regional mapping of rainfall-induced landslides using TRIGRS model. Arabian Journal of Geosciences, 8(5), 3183-3194.

xlii. Saadatkhah, N., Kassim, A., \& Lee, L. M. 2014b. Hulu Kelang, Malaysia regional mapping of rainfall-induced landslides using TRIGRS model. Arabian Journal of Geosciences, 8(5), 3183-3194.

xliii. Salem Almohaifer, Mohammad, Mohamed A. Islam, Abul Kalam Azad, Ahmad Dahlan, and Abdul Rahman. "COLLABORATIVE DISASTER MANAGEMENT SYSTEM-AN EXPLORATORY FOR LANDSLIDE IN MALAYSIA." InInternational Management Conference 2011, pp. 1-17. University Sultan Zainal Abidin, 2011.

xliv. Simon, N., Crozier, M., Roiste, M., Rafek, A. G., \& Roslee, R. 2015. Time series assessment on landslide occurrences in an area undergoing development. Singapore Journal of Tropical Geography, 36(1), 98-111.

xlv. Zhou, C. H., C. F. Lee, J. Li, and Z. W. Xu. "On the spatial relationship between landslides and causative factors on Lantau Island, Hong Kong."Geomorphology 43, no. 3 (2002): 197-207.

xlvi. http:// www.preventionweb.net/ organizations/ 5959.

xlvii. Slope Engineering Branch, 2009. "Landslide Statistics in Malaysia for 2007 and 2008” Public Works Department, Malaysia

xlviii. Public Works Department, 2008. Draft National Slope Master Plan, Slope Engineering Branch, JKR Malaysia

xlix. Mohamed, A. and Abdullah, C. H., 2009. "Landslide and National Slope Policy." Seminar on Safe Hill-Site Development, February 14, 2009, Subang Jaya, Selangor, Malaysia.

1. Public Works Department, 2006. Terms of reference for National Slope Master Plan Study. JKR Memorandum of Agreement, No:JKR/ IP/ CKC/ 23/ 2006.JKR Malaysia 